\title{
Increase in Mortality Rate Following Coprescription of Cisapride and Contraindicated Drugs
}

\author{
Nam-Kyong Choi, Seokyung Hahn, and Byung-Joo Park
}

C isapride is an oral prokinetic agent used for the symptomatic treatment of nocturnal heartburn due to gastroesophageal reflux disease. ${ }^{1}$ It was first approved in Korea in June 1989 and was introduced to the US market in August 1993. Since cisapride's introduction, 341 cases of ventricular arrhythmias, including 80 deaths, have been reported to the Food and Drug Administration (FDA). Many of these cases had involved drugs known to inhibit CYP3A4, which metabolizes cisapride. ${ }^{2}$ Four label changes and physician notifications (Dear Doctor letters) were issued in February and October 1995, June 1998, and June 1999 in the US. ${ }^{3}$ The Korean drug regulatory agency modified cisapride's label 3 times in 2000 and distributed prescription guidelines to physicians. While such risk management efforts were being made, Janssen Pharmaceutica, a major manufacturer of cisapride, voluntarily discontinued commercial marketing of the product in the US in July 2000. Janssen Korea withdrew the drug in October 2000.

After cisapride was withdrawn from the general market, the manufacturer provided it, with proper indication for its use, to patients who were unresponsive to other therapies and had normal electrocardiogram results. ${ }^{4}$ Apart from that specific use, the distributors' stocks of the drug also remained available for general users, and no particular actions were taken on generic products.

Author information provided at the end of the text.
BACKGROUND: No epidemiologic study, as of this writing, has been published on the use of cisapride with contraindicated drugs and its relation to mortality rates in a population-based setting.

OBJECTIVE: To estimate the prevalence of concomitant use of cisapride with contraindicated drugs and evaluate the association between this and the risk of mortality.

METHODS: Claims data were obtained from the Health Insurance Review Agency of Korea. The study population consisted of patients younger than 85 years who visited clinics or hospitals in the city of Busan as new users of cisapride between November 1, 2000, and April 30, 2002. The coprescription of cisapride was defined as prescribing cisapride with one or more contraindicated drugs with the same prescription. Nationwide mortality data were also used. The prevalence of coprescribing cisapride was estimated and the association between this and the risk of mortality was assessed by rate ratios (RRs). The RRs were estimated using Cox's regression model with time-dependent covariate, adjusted for age, sex, and comorbidities.

RESULTS: A total of 36865 patients out of 56012 claims were newly prescribed cisapride; of these, 1175 patients $(3.2 \%)$ were concomitantly prescribed at least one contraindicated drug, which suggested adjusted mortality RRs of 14.08 (95\% $\mathrm{Cl} 7.41$ to 26.76 ) for recent users and 1.33 (95\% Cl 0.92 to 1.93) for past users of cisapride.

CONCLUSIONS: Despite the discontinuation of the drug's commercial marketing, cisapride was still in use in clinics and hospitals in Busan. In many cases, cisapride was co-prescribed with contraindicated drugs, which is associated with increased mortality rates.

KEY WORDS: cisapride, contraindications, mortality.

Ann Pharmacother 2007;41:667-73.

Published Online, 20 Mar 2007, www.theannals.com, DOI 10.1345/aph.1H247 
these cases involved contraindicated drugs. However, to the best of our knowledge, there has been no published epidemiologic study on the use of cisapride with contraindicated drugs and mortality in a population-based setting. A properly designed study was necessary to identify the risk of mortality associated with concomitant use of cisapride and contraindicated drugs.

This study was conducted to estimate the prevalence of the use of cisapride with contraindicated drugs and evaluate the association between this coprescription and the risk of all-cause mortality.

\section{Methods}

\section{DATABASE}

Korea's Health Insurance Review Agency (HIRA) was established on July 1, 2000, to combine claims data review and healthcare assessment, under the responsibility of a single agency independent from insurers, providers, and other interested parties. All Koreans are entitled to be either an employed member or a community member under the national health insurance system. When any beneficiary demonstrates signs and/or symptoms that indicate a need for medical care, the patient is provided with regional medical services and the providers then submit claims to the HIRA for a review of the incurred medical costs. Therefore, the HIRA database contains all information on claims made, as well as on prescriptions.

We obtained a database containing claims data submitted by health providers based in Busan under the condition of confidentiality on patient information. Our study was exempt from review by the institutional review board of Seoul National University Hospital at the time of its planning, because it fell under the remission criteria as a retrospective study using an existing dataset for academic purposes that did not involve personal information. The data were provided after deleting the last digit of each patient's citizen registration number so that the code could be used only for data sorting and linking purposes without revealing the individual identity of each patient. Only authorized researchers had access to the database for analysis.

The city of Busan is 450 kilometers southeast of Seoul, the nation's capital, and is the second largest city in Korea, with a population of 3.81 million as of 2001 . The database includes the patients' citizen registration number (without the last digit), age, sex, clinic registration number, diagnosis, and list of prescribed drugs. The information provided on the drugs included brand name, generic name, prescription date, and duration and route of administration. Diagnoses were coded according to the International Classification of Disease, Tenth Revision (ICD-10).

\section{COHORT}

The study population was defined as patients younger than 85 years who visited clinics or hospitals in the Busan metropolitan area between November 1, 2000, and April 30,2002 , as new users of cisapride. New cisapride users were defined as patients who took cisapride during this period for the first time without a history of having been prescribed the drug during the preceding 3 months.

From nearly 20 million prescriptions with valid records in the database, we identified every prescription of cisapride during the study period. All prescriptions relating to the same patient were identified using the key based on the citizen registration number and were linked together. We extracted information on 55393 patients and 93608 relevant prescriptions. We then excluded 18528 patients who did not meet the criteria (18 434 were not new cisapride users and 94 were $>85 \mathrm{y}$ of age). The final study cohort included 36865 new cisapride users and 56012 prescriptions.

\section{DRUG EXPOSURE}

Coprescription of cisapride was defined as the prescription of cisapride with at least one contraindicated drug on the same prescription. The contraindicated drugs that were considered in the study were based on Notification No. 2004-2 announced by the Korea Ministry of Health and Welfare (Table 1). The selection was made based on chemical equivalency regardless of label or package.

\section{IDENTIFICATION OF DEATH}

Nationwide mortality data from November 1,2000 , to December 31, 2002, provided by the Korea National Statistical Office, were used. The data included the patient's

Table 1. Medications Contraindicated with Cisapride ${ }^{a}$

\begin{tabular}{|c|c|}
\hline $\begin{array}{l}\text { Therapeutic } \\
\text { Category }\end{array}$ & Medication \\
\hline Anti-allergics & $\begin{array}{l}\text { astemizole, terfenadine, mequitazine, } \\
\text { promethazine }\end{array}$ \\
\hline Antiarrhythmics & $\begin{array}{l}\text { amiodarone } \mathrm{HCl} \text {, disopyramide, procainamide, } \\
\text { sotalol, quinidine, terfenadine }\end{array}$ \\
\hline Antibacterial & sparfloxacin \\
\hline Antibiotics & $\begin{array}{l}\text { clarithromycin, erythromycin, erythromycin } \\
\text { estolate, erythromycin stinoprate }\end{array}$ \\
\hline Antidepressants & $\begin{array}{l}\text { amitriptyline } \mathrm{HCl} \text {, fluvoxamine maleate, } \\
\text { imipramine } \mathrm{HCl} \text {, maprotiline, nefazodone }\end{array}$ \\
\hline Antifungals & fluconazole, itraconazole, ketoconazole \\
\hline Antinausea & prochlorperazine \\
\hline Antipsychotics & pimozide, perphenazine \\
\hline Protease inhibitors & indinavir, nelfinavir \\
\hline
\end{tabular}


citizen registration number (without the last digit), cause of death coded according to ICD -10 standards, and date of death. All-cause mortality was defined as any disease-related death, excluding accidental deaths caused by traffic accidents, other external causes of accidental injury, intentional self-harm, and assaults.

\section{STATISTICAL ANALYSES}

The prevalence of the coprescription of cisapride was estimated as the proportion of co-prescribed patients out of the total number of new users of cisapride. The association between cisapride coprescription and the risk of mortality was measured by rate ratios (RRs). The RRs with $95 \%$ confidence intervals were estimated using Cox's regression model with time-dependent covariate. The point of time for each coprescription was considered in the analysis to account for a possible difference in the risk of death during or outside the period of combined use. Consecutive start and end times of co-prescriptions were recorded for each subject to indicate every change in time-dependent exposure over the study period. The model included one time-dependent covariate (exposure) and several fixed covariates (confounders):

$$
\begin{gathered}
\log h(t)=\alpha(t)+\beta_{1} X_{1}(t)+\beta_{2} X_{2}+\beta_{3} X_{3}+ \\
\beta_{4} X_{4}+\beta_{5} X_{5}+\beta_{6} X_{6}+\beta_{7} X_{7}
\end{gathered}
$$

which estimates the hazard at time $t$ depending on the value of $X_{1}$ at $t$ and on the values of $X_{2}, X_{3}, X_{4}, X_{5}, X_{6}$, and $X_{7} \cdot X_{1}(t)=1$ if on combined use at time $t ; 0$ otherwise.

The follow-up time for each individual was from the date of the first cisapride prescription until the earliest of the following dates: death, 85th birthday, or December 31, 2002. The RRs were adjusted for age, sex, and comorbidities such as heart, respiratory system, and digestive system disease, as well as neoplasms. Comorbidity data were constructed from records of diagnosis made at the time of cisapride prescription. Heart disease, respiratory system disease, digestive system disease, and neoplasms were defined according to the ICD-10 diagnosis codes.

We performed separate analysis that took into account the time lapse between the time of last combined use and time of death, adjusted for age, sex, and comorbidities. The combined users were classified into 2 categories; recent users (last combined use within 30 days of death) and past users (beyond 30 days). Statistical analysis was performed using the SAS statistical application program (Release 9.1, SAS Institute Inc, Cary, NC).

\section{Results}

A total of 36865 patients were newly prescribed cisapride between November 1, 2000, and April 30, 2002; the number of cisapride prescriptions administered to these pa- tients was 56 012. Among the total cohort, $58.8 \%$ were female, with a mean \pm SD age of $28.5 \pm 24.1$ years. Among the new cisapride users, $1175(3.2 \%)$ were prescribed at least one contraindicated drug with cisapride, which made up $1635(2.9 \%)$ of the total claims. The 3 contraindicated drugs most commonly co-prescribed with cisapride were amitriptyline (486 claims), mequitazine (308), and terfenadine (292; Table 2).

There was a significant age difference $(\mathrm{p}<0.001)$ between the groups of cisapride users who were prescribed contraindicated drugs and those who were not. Among the new users of cisapride who did not take contraindicated drugs, $48.6 \%$ were $0-24$ years old and $9.2 \%$ were $65-84$ years old. However, $27.5 \%$ of the co-prescribed users were $0-24$ years old, and $17.9 \%$ were $65-84$ years old. The proportion of contraindicated drug users did not differ significantly according to sex $(\mathrm{p}=0.13)$ or comorbidities such as respiratory system disease $(\mathrm{p}=0.86)$ and neoplasms $(\mathrm{p}=0.16)$. Comorbid digestive system disease was more likely to be found in users who were not prescribed contraindicated drugs $(\mathrm{p}<0.001)$, and heart disease was found more often in those prescribed contraindicated drugs $(\mathrm{p}=0.002$; Table 3$)$.

The frequency with which cisapride was co-prescribed with contraindicated drugs varied throughout different age groups. Patients aged 65-84 years had the highest prevalence of coprescription (6.0\%), while the lowest prevalence (1.8\%) was for the group aged 0-24 years. Among patients with respiratory system diseases, $3.2 \%$ used contraindicated drugs. The prevalence of coprescribing cisapride with contraindicated drugs in those with digestive system disease, heart disease, and neoplasms was $2.5 \%$, $6.1 \%$, and $4.4 \%$, respectively (Table 3 ).

\begin{tabular}{|cc|}
\hline $\begin{array}{c}\text { Table 2. Frequency of Coprescribed Contraindicated } \\
\text { Medications Among New Users of Cisapride }\end{array}$ \\
\hline $\begin{array}{c}\text { Contraindicated } \\
\text { Medication }\end{array}$ & Pts., $\mathbf{n}(\%)$ \\
\hline Amitriptyline $\mathrm{HCl}$ & $486(28.8)$ \\
Mequitazine & $308(18.3)$ \\
Terfenadine & $292(17.3)$ \\
Erythromycin & $174(10.3)$ \\
Clarithromycin & $142(8.4)$ \\
Fluconazole & $86(5.1)$ \\
Perphenazine & $59(3.5)$ \\
Imipramine HCl & $43(2.6)$ \\
Fluvoxamine maleate & $39(2.3)$ \\
Ketoconazole & $28(1.7)$ \\
Itraconazole & $18(1.1)$ \\
Amiodarone HCl & $6(0.4)$ \\
Nefazodone & $2(0.1)$ \\
Promethazine & $1(0.1)$ \\
Sotalol & $1(0.1)$ \\
Sparfloxacin & $1(0.1)$ \\
TOTAL & $1686(100.0)$ \\
\hline
\end{tabular}


The relationship between cisapride coprescription and mortality risk is shown in Table 4 . The total number of deaths was 564. There had been no accidental deaths found. Forty-four patients out of the 564 were co-prescribed cisapride with contraindicated drugs, giving a crude RR of 2.63 (95\% CI 1.91 to 3.63). The adjusted RR was 1.73 (95\% CI 1.25 to 2.40). The adjusted RRs were 14.08 (95\% CI 7.41 to 26.76) for recent cisiapride users and 1.33 (95\% CI 0.92 to 1.93 ) for past users.

\section{Discussion}

The results of this retrospective population-based cohort study showed that, despite the discontinuation of the commercial marketing of cisapride by Janssen Pharmaceutica, cisapride was still newly prescribed to 36865 patients in the Busan area between November 1, 2000, and April 30, 2002. We also found that $3.2 \%$ of these patients were coprescribed cisapride with contraindicated drugs. The recent coprescription of contraindicated drugs increased the risk of all-cause mortality compared with the prescription of cisapride without contraindicated drugs. However, the risk was not significant after 30 days from the time of last combined use.

We observed that the concomitant users were older and more likely to have heart disease than were those who were not prescribed contraindicated drugs. This might be related to the higher risk of mortality in those prescribed contraindicated drugs. To minimize the possibility of such confounding effects, we adjusted the results for age, sex, and comorbidities; the overall adjusted RR became smaller than the crude RR, but significantly greater than 1, suggesting that interaction caused by the use of cisapride with contraindicated drugs might contribute to death. We also conducted a separate analysis based on the indication of heart disease and the result showed that the combined use was still a risk factor in patients who did not have heart disease (adjusted RR 1.74; 95\% CI 1.25 to 2.44 ).

In order to investigate a causal relationship, it is important to know whether the deaths occurred during at-risk periods. In our study, the status of the combined medication use varied with time, and therefore an additional level of

\begin{tabular}{|c|c|c|c|c|}
\hline \multirow[b]{2}{*}{ Variable } & \multicolumn{2}{|c|}{ Pts., n (\%) } & \multirow[b]{2}{*}{ p Value ${ }^{a}$} & \multirow{2}{*}{$\begin{array}{c}\text { Prevalence of } \\
\text { the Use of } \\
\text { Cisapride with } \\
\text { Contraindicated } \\
\text { Drugs (\%) }\end{array}$} \\
\hline & $\begin{array}{l}\text { Cisapride Prescribed Without } \\
\text { Contraindicated Drugs }\end{array}$ & $\begin{array}{l}\text { Cisapride Prescribed with } \\
\text { Contraindicated Drugs }\end{array}$ & & \\
\hline Age, y & $28.1 \pm 23.9^{b}$ & $39.9 \pm 24.2^{b}$ & $<0.001$ & \\
\hline $0-24$ & $17360(48.6)$ & $323(27.5)$ & $<0.001$ & 1.8 \\
\hline $25-44$ & 8204 (23.0) & $283(24.1)$ & & 3.3 \\
\hline $45-64$ & 6827 (19.1) & 359 (30.6) & & 5.0 \\
\hline $65-84$ & $3299(9.2)$ & $210(17.9)$ & & 6.0 \\
\hline \multicolumn{5}{|l|}{ Sex } \\
\hline male & $14732(41.3)$ & $459(39.1)$ & 0.13 & 3.0 \\
\hline female & 20958 (58.7) & $716(60.9)$ & & 3.3 \\
\hline \multicolumn{5}{|l|}{ Comorbidities } \\
\hline respiratory system disease & $15036(42.1)$ & $498(42.4)$ & 0.86 & 3.2 \\
\hline digestive system disease & $22294(62.5)$ & $579(49.3)$ & $<0.001$ & 2.5 \\
\hline heart disease & $306(0.9)$ & $20(1.7)$ & 0.002 & 6.1 \\
\hline neoplasms & $366(1.0)$ & $17(1.4)$ & 0.16 & 4.4 \\
\hline TOTAL & $35690(100.0)$ & $1175(100.0)$ & & 3.2 \\
\hline
\end{tabular}

\begin{tabular}{|c|c|c|c|c|c|}
\hline Variable & $\begin{array}{l}\text { Person- } \\
\text { years }\end{array}$ & Subjects, $n$ & Deaths, $n$ & $\begin{array}{c}\text { Crude RR } \\
(95 \% \mathrm{Cl})\end{array}$ & $\begin{array}{l}\text { Adjusted RR }^{\mathrm{a}} \\
(95 \% \mathrm{Cl})\end{array}$ \\
\hline Cisapride without contraindicated drugs & 57650 & 35690 & 520 & 1.00 & 1.00 \\
\hline Cisapride with contraindicated drugs & 1873 & 1175 & 44 & 2.63 (1.91 to 3.63$)$ & $1.73(1.25$ to 2.40$)$ \\
\hline recent users $(0 \leq t \leq 30$ days $)$ & 8 & 13 & 10 & 118.94 (63.5 to 222.6$)$ & $14.08(7.41$ to 26.76$)$ \\
\hline past users $(30<$ t days $)$ & 1865 & 1162 & 34 & 1.99 (1.37 to 2.87$)$ & $1.33(0.92$ to 1.93$)$ \\
\hline
\end{tabular}


complexity was introduced due to the need to account for time-dependent exposure in Cox's regression model. ${ }^{10,11}$ Time-dependent covariates change in value over the course of observation. Subgroup analyses were also performed based on the time lapse between last combined use and death. From the present results, we conclude that there could be a link between the combined use of cisapride with contraindicated drugs and death.

Cisapride is metabolized by the CYP3A4 enzyme system, and the concomitant use of drugs that inhibit these enzymes can increase plasma cisapride concentrations and induce QT interval prolongation. ${ }^{2,5}$ In 1995, therefore, a black box warning was added to the labeling on cisapride products, stating that certain drugs that inhibit the enzymes were contraindicated with cisapride because they could potentially cause fatal arrhythmia; a list of the contraindicated drugs was included with this warning.'

The combined use of cisapride with other medications known to prolong the QT interval could also have additive effects on QT interval. ${ }^{12}$ In June 1998, the use of class IA and class III antiarrhythmic drugs and drugs known to prolong the QT interval, as well as certain medical conditions (ie, history of prolonged QT intervals, ventricular arrhythmia, ischemic heart disease, renal failure, congestive heart failure, respiratory failure, uncorrected electrolyte disorders) were added to the black box warning as contraindications.'

Several studies have reported the estimated prevalence of coprescribing cisapride with contraindicated drugs. In the US, a retrospective study of prescription claims from a managed-care organization database for all patients with cisapride prescriptions between July 1993 and December 1998 was conducted and published. ${ }^{13}$ Of 131485 cisapride prescriptions dispensed after the warnings began, 4414 (3.4\%) overlapped with at least 1 contraindicated drug on the labels at the time of the prescription. In the Netherlands, among cisapride users from 1994 to 1998, 944 (3.1\%) patients used 1 or more potentially interacting drugs..$^{14}$ Compared with these studies, our study focused on a specific period following the removal of cisapride from the market; the results highlighted the fact that cisapride was co-prescribed with contraindicated drugs after cisapride's market withdrawal in proportions similar to those found in the previous studies.

Although our results were derived from an observational study, the study's strength is in the fact that it was the first population-based study to investigate the association between the coprescription of cisapride with contraindicated drugs and mortality. We studied an entire target population, rather than a sampled one, that was prescribed cisapride in a chosen area during the study period. While several case reports and postmarketing safety data have suggested the link between cisapride and QT interval prolongation and torsade des pointes, ${ }^{2,9,15,16}$ they did not evaluate the outcome of coprescribing cisapride with potential interacting drugs.
When relying on spontaneous reports, it is not practical to estimate population risks because considerable underreporting of adverse events is likely. For example, in the case of arrhythmia, underreporting could be an even more serious factor because sudden cardiac deaths are often reported without documentation of arrhythmia. ${ }^{9}$ Our study period was limited to the period following the discontinuation of the commercial marketing of cisapride, which enabled us to observe the impact of the discontinued marketing on the use of the drug and estimate the prevalence of the use of cisapride with contraindicated drugs. We restricted our analysis to new users of cisapride, in order to maintain control of the various underlying conditions of patients as long-term users and of any possible bias in the selection regarding early emergence symptoms, drug intolerance, or treatment failure. ${ }^{17}$

Our results should also be interpreted with some limitations in mind. Even though we tried to make adjustments to minimize confounding effects, the information on potential confounding factors that we used might not have been complete. For example, we considered diagnoses as reported to HIRA, which might differ from the patients' actual diagnosis. A validation study compared the diagnosis derived from the HIRA database with the actual diagnosis in the patients' medical records..$^{18}$ Positive predictive value (PPV) was calculated according to disease groups. The PPV was $77.6 \%$ for neoplasm, $67.4 \%$ for stroke, and $58.6 \%$ for rheumatoid arthritis. The overall PPV of the diagnoses was $81.8 \%$ in the case of inpatients. However, the diagnosis may not provide sufficient information on the severity of individual disease status and medical history. However, because the Korean drug regulatory agency had already warned against the combined use of cisapride and contraindicated drugs through new labels and by distributing prescription guides to physicians, any remaining confounders may have little impact.

We chose mortality as the event of interest. It might have been more reasonable to consider serious ventricular arrhythmia or prolongation of the QT interval as the outcome to evaluate the effect of coprescription in cisapride users. However, one known reason for the failure of previous observational studies ${ }^{19-22}$ to confirm or refute the association between cisapride and cardiac adverse events was outcome misclassification. ${ }^{23}$ The difficulty of accurately diagnosing QT prolongation would have had a significant impact on misclassification. Furthermore, a variety of terms were used for outcomes associated with cardiac toxicity, and it appeared that some relevant outcomes were often not included, thus contributing to the failure of these studies in confirming the hypothesis. Mortality is clearly defined and easily traceable to avoid such classification problems, but it might be questionable for all-cause mortality to be used as an outcome of a direct effect of the coprescription. 


\section{Conclusions}

We found that, despite the discontinuation of its commercial marketing, cisapride was still in use through available sources; in many cases, it was co-prescribed with contraindicated drugs. Our findings also suggested that drug interactions with the contraindicated co-prescribed drugs might contribute to an increase in the risk of mortality. Cisapride has been withdrawn in most major markets, but it is still used via a limited-access protocol. Cisapride should be prescribed to carefully chosen patients and should not be prescribed with contraindicated drugs.

Nam-Kyong Choi, PhD Student, Department of Preventive Medicine, College of Medicine, Seoul National University, Seoul, Korea Seokyung Hahn PhD, Assistant Professor, Medical Research Collaborating Center, College of Medicine, Seoul National University/Seoul National University Hospital

Byung-Joo Park MD PhD, Professor, Department of Preventive Medicine, College of Medicine, Seoul National University; Director, Medical Research Collaborating Center, College of Medicine, Seoul National University/Seoul National University Hospital

Reprints: Dr. Hahn, Medical Research Collaborating Center, 2nd Floor, Samsung Cancer Research Institute, College of Medicine, Seoul National University, 28 Yongon Dong, Chongno Gu, Seoul 110-744, Korea, fax 82-2-743-8361, hahns@ @nu.ac.kr

This study was supported by grant no 03-2004-021-0 from Seoul National University Hospital Fund.

Presented at the 20th International Conference on Pharmacoepidemiology and Therapeutic Risk Management 2004 Annual Meeting, Bordeaux, France, August 22-25, 2004.

\section{References}

1. Physician's desk reference. 54th ed. Montvale, NJ: Medical Economics, 2000:1451-3

2. van Haarst AD, van't Klooster GA, van Gerven JM, et al. The influence of cisapride and clarithromycin on QT intervals in healthy volunteers. Clin Pharmacol Ther 1998;64:542-6.

3. Gex-Fabry M, Balant-Gorgia AE, Balant LP. Therapeutic drug monitoring databases for postmarketing surveillance of drug-drug interactions. Drug Saf 2001;24:947-59.

4. Food and Drug Administration. Janssen Pharmaceutica stops marketing cisapride in the US [talk paper, 1 page]. 2000 Mar 23. www.fda.gov/bbs/ topics/ANSWERS/ANS01007.html (accessed 2005 Dec 21).

5. Gross AS, Goh YD, Addison RS, Shenfield GM. Influence of grapefruit juice on cisapride pharmacokinetics. Clin Pharmacol Ther 1999;65:395401.

6. Piquette RK. Torsade de pointes induced by cisapride/clarithromycin interaction. Ann Pharmacother 1999;33:22-6. DOI 10.1345/aph.18107

7. Kyrmizakis DE, Chimona TS, Kanoupakis EM, Papadakis CE, Velegrakis GA, Helidonis ES. QT prolongation and torsades de pointes associated with concurrent use of cisapride and erythromycin. Am J Otolaryngol 2002;23:303-7.

8. Enger C, Cali C, Walker AM. Serious ventricular arrhythmias among users of cisapride and other QT-prolonging agents in the United States. Pharmacoepidemiol Drug Saf 2002;11:477-86.

9. Wysowski DK, Corken A, Gallo-Torres H, Talarico L, Rodriguez EM. Postmarketing reports of QT prolongation and ventricular arrhythmia in association with cisapride and Food and Drug Administration regulatory actions. Am J Gastroenterol 2001;96:1698-703.

10. White E, Hunt JR, Casso D. Exposure measurement in cohort studies: the challenges of prospective data collection. Epidemiol Rev 1998;20: 43-56.
11. Fisher LD, Lin DY, Time-dependent covariates in the Cox proportionalhazards regression model. Annu Rev Public Health 1999;20:145-57.

12. Michalets EL, Williams CR. Drug interactions with cisapride: clinical implications. Clin Pharmacokinet 2000;39:49-75.

13. Jones JK, Fife D, Curkendall S, Goehring E Jr, Guo JJ, Shannon M. Coprescribing and codispensing of cisapride and contraindicated drugs. JAMA 2001;286:1607-9.

14. De Bruin ML, Panneman MJ, Leufkens HG, Hoes AW, Herings RM Use of cisapride with contraindicated drugs in The Netherlands. Ann Pharmacother 2002;36:338-43. DOI 10.1345/aph.1A246

15. Bran S, Murray WA, Hirsch IB, Palmer JP. Long QT syndrome during high-dose cisapride. Arch Intern Med 1995;155:765-8.

16. Vitola J, Vukanovic J, Roden DM. Cisapride-induced torsades de pointes. J Cardiovasc Electrophysiol 1998;9:1109-13.

17. Ray WA. Evaluating medication effects outside of clinical trials: newuser designs. Am J Epidemiol 2003;158:915-20.

18. Park BJ, Sung JH, Park KD, Seo SW, Kim SW. Report of the evaluation for validity of discharged diagnoses in Korean Health Insurance database. Seoul: Seoul National University, 2003:19-52.

19. Inman W, Kubota K. Tachycardia during cisapride treatment (letter). BMJ 1992;305:1019.

20. Liehr H, Schmidt R. A German drug-monitoring study in general practice patients receiving cisapride for functional dyspepsia. Scand J Gastroenterol Suppl 1993;195:54-8.

21. Walker AM, Szneke P, Weatherby LB, et al. The risk of serious cardiac arrhythmias among cisapride users in the United Kingdom and Canada. Am J Med 1999;107:356-62.

22. Tooley PJ, Vervaet P, Wager E. Cardiac arrhythmias reported during treatment with cisapride (letter). Pharmacoepidemiol Drug Saf 1999;8: 57-60.

23. Layton D, Key C, Shakir SA. Prolongation of the QT interval and cardiac arrhythmias associated with cisapride: limitations of the pharmacoepidemiological studies conducted and proposals for the future. Pharmacoepidemiol Drug Saf 2003;12:31-40.

\section{EXTRACTO}

TRASFONDO: No se había publicado un estudio epidemiológico sobre el uso de cisapride concurrentemente con drogas contraindicadas y su relación con tasas de mortalidad en un contexto poblacional.

OBJETIVOs: Estimar la prevalencia del uso de cisapride concurrentemente con drogas contraindicadas y evaluar la asociación entre la prescripción de cisapride concurrentemente con drogas contraindicadas y el riesgo de mortalidad.

MÉTODos: Se obtuvieron datos provenientes de reclamaciones ante la Agencia Revisora del Seguro de Salud de Korea. La población bajo estudio consistió de pacientes menores de 85 años de edad que visitaron clínicas y hospitales en la ciudad de Busan como usuarios nuevos de cisapride entre el primero de noviembre de 2000 y el 30 de abril de 2002. La prescripción concurrente de cisapride fue definida como prescribir cisapride con una o más drogas contraindicadas en la misma receta. También se utilizaron datos de mortalidad a nivel nacional. Se estimó la prevalencia de la prescripción concurrente de cisapride y la asociación entre la prescripción de cisapride concurrentemente con drogas contraindicadas y el riesgo de mortalidad, fue evaluado mediante razones de tasas. Las razones de tasas fueron estimadas usando el modelo de regresión de Cox con variables dependientes del tiempo, ajustadas por edad, género y comorbilidades.

RESULTADOS: De 56012 reclamaciones, un total de 36865 correspondían a pacientes que eran usuarios nuevos de cisapride, de los cuales a 1175 pacientes $(3.2 \%)$ se les prescribió por lo menos una droga contraindicada concurrentemente con cisapride. Esto sugirió una razón de tasas de mortalidad ajustada de 14.08 (IC $95 \% 7.41$ y 26.76) para usuarios recientes y 1.33 (IC $95 \% 0.92$ y 1.93) para aquellos que habían usado la droga en el pasado.

CONCLUSIONES: A pesar de que se descontinuó el mercadeo comercial de la droga, cisapride aún sigue en uso y en muchos casos, es prescrita 
concurrentemente con drogas contraindicadas. Esta prescripción concurrente está asociada con mortalidad.

Ana E Vélez

\section{RÉSUMÉ}

GÉNÉRALITÉs: Aucune étude épidémiologique n'a été publiée sur l'usage du Cisapride avec des médicaments contre-indiqués et sa relation avec les taux de mortalité sur une base de la population.

OBJECTIF: Estimer la prévalence de l'usage du Cisapride avec des médicaments contre-indiqués et évaluer l'association entre la coprescription du Cisapride-médicaments contre-indiqués et le risque de mortalité.

MÉTHODES: Des arguments de données furent obtenus à l'aide de l' Agence de Surveillance de la Santé et des Assurances de la Corée du Sud (HIRA). La population d'étude a consisté de patients de moins de 85 ans qui ont été consultés dans des cliniques ou hôpitaux de la ville de Busan et qui ont été de nouveaux utilisateurs du Cisapride entre 1 novembre 2000 et 30 avril 2002. La co-prescription du Cisapride fut définie comme prescrit avec un ou plusieurs médicaments contre- indiqués et ce, sur la même ordonnance. Les données de mortalité à l'échelle nationale furent également utilisées. La prévalence de la coprescription du Cisapride fut estimée et l'association entre la coprescription du Cisapride-médicaments contre-indiqués et le risque de mortalité fut évaluée à l'aide du ratio des taux. Les ratios des taux furent estimés en utilisant le modèle de régression de Cox utilisant une covariable dépendante du temps, ajustée sur age, sexe, et comorbidités.

RÉSULTATS: Sur 56012 demandes de remboursement, le Cisapride fut nouvellement prescrit chez un total de 36865 patients, parmi lesquels $1175(3.2 \%)$ reçurent un médicament contre-indiqué avec le Cisapride au moins une fois. Ceci suggère un taux de mortalité ajusté de 14.8\% (CI 95\% 7.41 à 26.76) chez les utilisateurs récents et 1.33\% (CI 95\% [0.92 à 1.93) chez les anciens utilisateurs.

CONCLUSIONS: En dépit de la suspension de la commercialisation du médicament, le Cisapride a été toujours utilisé et, dans plusieurs cas, a été coprescrit avec des médicaments contre-indiqués. La co-prescription étant associée avec une mortalité.

Thierry Youmbi

\title{
MEDICAL ABBREVIATIO
28,000 Conveniences at the Expense of Communications and Safety
}

\section{3th Edition • By Neil M. Davis}

360 pp / Paperbound / ISBN 0-931431-13-1 / 2007 / \$26.95

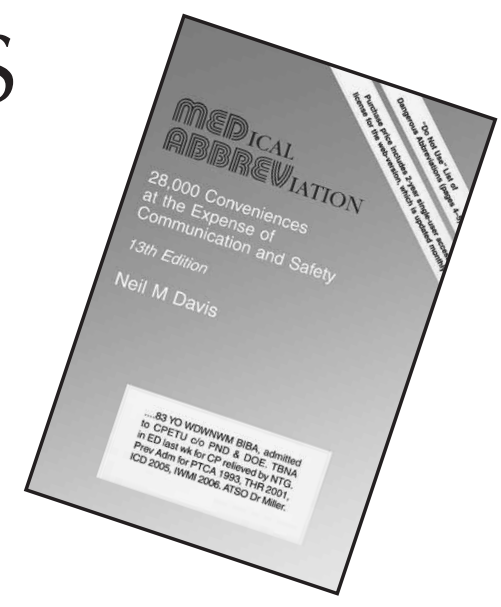

The 13th edition includes a "do not use" list of dangerous abbreviations in addition to the 28,000 meanings for the abbreviations, acronyms, and symbols. The book also contains a cross-referenced list of 3,400 generic and trade drug names. Each copy includes a single-user access license for the web version of the book which is updated with over 100 new entries per month. This license is valid for 24 months from the date of initial log-in.

Essential to medical professionals for order interpretation, data entry, unit dose cart filling, and prescription interpretation. A must to ensure patient safety and reduce medication errors.

\section{ORDER ONLINE AND SAVE 10\% ON YOUR PURCHASE}

\author{
Harvey Whitney Books Company \\ PO Box 42696 Cincinnati OH 45242-0696 \\ Order Toll-Free: 877-742-7631 \\ www.hwbooks.com
}

